SCHOLARS: Journal of Arts \& Humanities

[Peer-Reviewed, Open Access, Indexed in NepJOL]

Central Department of English

Print ISSN: 2773-7829; e-ISSN: 2773-7837

Volume 1, August 2019, pp. 41-49

Tribhuvan University

DOI: https://doi.org/10.3126/sjah.v1i0.34447

Kirtipur, Kathmandu, Nepal

www.cdetu.edu.np/ejournal/

\title{
Growing up South Asian: A Brief Trajectory Drawn from South Asian Novels Targeted for Youths
}

\author{
Hari R. Adhikari, PhD \\ Department of English \\ Ratna Rajyalaxmi Campus, Kathmandu, Nepal
}

\begin{abstract}
:
This paper primarily presents the trajectory of growing up in South Asia drawing insights from the selected novels about South Asian youths (SA youths). In this process, the paper explores the political interest of the West in non-Western children and youths. The focus is on the exploration of whether contemporary youth literatures have still been reinforcing the image of SA youths as the Other of the European youths, or if there has been any significant change augmented by the recent phenomenon of global connectedness. By laying a framework of these forces for analyzing how they are reflected in the literatures for the South Asian youths by foreign, diaspora and home authors, this paper prepares a ground for further exploration.
\end{abstract}

Keywords: South Asian youths, the Other, the non-West, dis-Orienting, subjectivity

\section{Introduction}

The coming-of-age, the transitional phase from childhood to adolescence, has always been an extremely productive space for politics. South Asian (SA) youths, for instance, have recently been in the spotlight among writers of literary narratives and producers of films and television programs in the West. Because of the region's more than three-hundred-year-old history of connection with the West, from imperialism to neo-colonialism and globalization, it is essential to make a reference to how the literature representing SA youths draws upon the notions of youth, childhood and children's literature developed around the periphery of the British Empire. "Childhood was an important ingredient in the making of empire, race and nationhood," Satadru Sen reminds us, "at a time when new meanings were attached to perceived distinctions between white and black children, girl and boy children, aristocratic and middle class 
Growing up South Asian: A Brief Trajectory 42

children, 'westernized' and 'authentic' children and between the offspring of the elite and those of the poor and provincial" (2). My main curiosity in this paper is whether this political interest of the West in non-Western children is still true, at a time when none of the countries in South Asia is directly under colonial occupation. For this, the paper will explore whether contemporary youth literatures have still been reinforcing the image of SA youths as the Other of the European youths, or if there has been any significant change augmented by the recent phenomenon of global connectedness.

Politically, the empires have shrunk back and the countries in South Asia almost all of which were once parts of Western empires - have become ostensibly free from direct colonial rules. However, SA youths, whether they live in South Asia, Europe, Africa, Australia, or the Americas, have always been subject to multiple layers of Othering in the normative discourses of Western Universalists and nationalists in SA countries. These youths encounter many such discourses everywhere, from home and neighborhoods to classrooms and school playgrounds. Most importantly, those youths who do not easily succumb to social rules are either "abjected" or hailed as being different from what they are, hailed by discourses as subtle as nursery rhymes and picture books to the ubiquitous media as well as national and international legal machineries. Especially since the nightmarish events of 9/11 in 2001, SA youths living in Europe and America have been in constant threat of being branded "terrorists." Thus, growing up SA entails a complex process of cast(e)ing and recast(e)ing the veils of various kinds such as race, class, caste, ethnicity, nationhood and the most significant of all, the veil of "aliens" while living in the Western World. It will be wrong to blame only the distant forces of colonialism or the domestic manifestations of neo-colonialism, for these youths constantly receive very "dis-Orienting” or Westernizing signals from their own parents, relatives and elders in their own communities. It is extremely vital that we study the ambivalence in the behavior of the elders in terms of adopting Western modernity to reform their old, restrictive and discriminatory cultural practices built around caste systems, arranged and child marriages, property rights and the lack of freedom of expression.

"Caste" and "veil" are the two major tropes commonly used in Western or "Westernized" political, cultural and literary discourses to describe "South Asianness." These tropes are often associated with two major religious and cultural groups, the Hindus and Muslims, which dominate the six nations in the region: Bangladesh, Bhutan, India, Maldives, Nepal and Pakistan, while in Sri Lanka, the Tamil Hindus are second after the dominant Sinhalese Buddhists. In these discourses, caste is allegedly responsible for the subjugation of one section of the population by another to the extent 
of rendering some people "untouchable." ${ }^{1}$ Caste practice was not only used by the upper caste Hindus to subjugate the so-called lower caste people, but, as Krishna Manavalli argues, it also became a primary subject of social classification and knowledge in colonial period. Manavalli writes, “. . . understanding caste allowed one [the British colonizer] better to control India” (68). Nicholas B. Dirks also suggests, "[I]t was under the British that 'caste' became a single term capable of expressing, organizing and above all 'systematizing' India's diverse forms of social identity, community and organization" (5). Caste is still a significant determining factor in shaping people's identities in most of the countries in the region. On the other hand, the "veil," basically refers to the mask worn by Muslim women to cover their body as a symbol of their cultural identity. However, the veil is seen as "symbolic of the suppression and exploitation of the 'oriental' woman both by man and, conversely, by the gaze of the Western colonialising and neo-imperialist world powers” (Grace 1).

Like literatures in general, the coming-of-age narratives representing South Asia are replete with these two major tropes, along with others like abuse, poverty and exile (both domestic and international displacement of people due to warfare or desire for economic advancement). In other words, the tropes of abuse, burqa, caste, poverty and exile appear in these narratives as if they are the signifiers of SA identity, in spite of the fact that "South Asia" is an amorphous category that transcends national boundaries of these seven countries. For instance, Afghanistan, Myanmar and Tibet also share demographic and topographic traits that are often identified as South Asians. Muslims in the Middle East and Arab world also wear veils, with some variations in form and significance. Likewise, abuse, poverty and exile (meaning displacement) are common phenomena all over the world. Considering the degree of their visibility in the narratives, I will primarily focus on the literatures that represent the youths in the five major countries in the Indian subcontinent: Bangladesh, India, Nepal, Pakistan and Sri Lanka².

${ }^{1}$ In Castes of Mind: Colonialism and the Making of Modern India, Nicholas B. Dirks lists the Hindu caste hierarchy as: the Brahmans, or the Brahmins as the most noble tribe who can officiate in the priesthood, the Ksatriyas as the second, who ought to be military men, the Baishyas or Vaisyas, as the third who are for the most part, merchants, bankers and bunias or shop-keepers and Sudras as the last tribe of the hierarchy who ought to be menial servants and that they are incapable to raise themselves to any superior rank.

${ }^{2}$ South Asia generally refers to seven countries namely, Bangladesh, Bhutan, India, the Maldives, Nepal, Pakistan and Sri Lanka under the umbrella SCHOLARS: Journal of Arts \& Humanities 
Growing up South Asian: A Brief Trajectory 44

Childhood and teen life in South Asia and SA families in the West are complex and pluralistic in nature. The patterns vary in terms of locations, dominant cultural practices and socio-economic levels. However, we cannot completely ignore the general picture because the stereotypes found in Western media and literatures are primarily based on such generalized attributes. What is the pattern of child-raising in South Asia in general? What do parents want their children to be? Do they want their children to resist Western values or do they want their children to assimilate Western cultures and values into their SA identities? In other words, how are these children oriented or (dis)oriented, for that matter? How are the recent trends of immigration and transnationalization of education and job markets complicating parent-child relations in this region? What could be those forces at work behind the social construction of the identities of SA youths and their relations with parents? And, who is responsible for the conflicts in families and beyond? This brief paper only lays foundation for a framework of these forcesso as to see how they are reflected in the literatures for the youths by foreign, diaspora and home authors.

Apparently, a huge percentage of SA youths subsist under the poverty line, which further complicates child-reading practices and parent-child relations. Most government programs targeting them depend on aid, in cash or goods, obtained from developed (mainly Western) countries ${ }^{3}$. As Judith Slater puts it, "Schooling in Asian countries is also influenced by colonization patterns or effects of occupation and war. The model of education adopted is usually based on that of the host country or it is some hybrid of the American or European system of education” (2). Urban children and to some extent even the children in rural areas, are gradually Westernized due to the hegemonic forces seeping in via cultural, academic, religious and family institutions. Children from rich families are educated in the West, or at least sent to English medium private schools inside the country. Many of those from the poor families go to poorly funded public schools or drop out and get married, get abducted by militia groups, get sold in brothels or are abused as child labors at home, in the community or elsewhere. They are discriminated on the basis of color, caste, class and gender. Thus, as SA children appear in the Western media, it seems like they need "rescuing" from all these forces that impede their individual growth.

In fact, the problem of representation is much more complicated than what it looks like on the surface. It is important to discuss the ways in which these children and

organization called South Asian Association for Regional Cooperation. Currently Afghanistan has also joined the organization as the eighth member nation.

${ }^{3}$ There has to be a separate study of what kind of programs get support and how they reflect underlying neo-colonial interests. 
Growing up South Asian: A Brief Trajectory 45

youths are disOriented, exoticized, infantilized and criminalized and parentified or adultified. It is, however, not to argue that these disOrienting forces are all essentially detrimental; for some of them have proven to be instrumental for the youths to find better means of survival in the contemporary world of globalization (which I would argue is more properly called "Westernization"). Overall, most of these processes have subjected the lives of SA youths, both at home and abroad, to victimization, alienation and discrimination. However, disOrientation and parentification have also empowered them to face the challenges posed by rapid globalization. This paper, however, will primarily focus on reviewing the literature representing SA youths' identity.

\section{South Asia and SA Youths in Literary Representations}

South Asia occupies a prominent space in postcolonial literature and theories of "alterity" in anthropology and in history as well as literary criticism. To borrow the term from Julia Kristeva, they represent an abject group in western literature. The one by whom the abject exists is the deject [the outcast] who places (himself), separates (himself), situates (himself) and therefore strays instead of getting its bearings, desiring, belonging, or refusing. . . . A tireless builder, the deject is in short a stray [a lost soul]. . . . And the more he strays the more he is saved (Kristeva, 8). More specifically, Arjun Apadurai's cultural-anthropological theory of "social imaginary," Bhabha's theorization of "hybridity," "mimicry," and "ambivalence," Guha and Spivak's theorization of "subalterneity," and Nandy's idea of "political psychology" have had significant influence in the Western academia, especially in the last few decades. In the same way, Rushdie, Roy, Desai, V. S. Naipaul, Michael Ondaatje, Jhumpa Lahiri, Bharati Mukherjee and Hanif Kureishi are some of the literary figures of South Asia and SA diaspora well established in the West. Other than in children's and young adult literature, much work has been done in other disciplines about the identities of SA youths since the days of Western imperial rule to the present era of globalization or neo-colonialism.

In Teen Life in Asia, Judith Slater, has made a comprehensive collection of anthropological narratives that explore the lives of the youths in Asia with separate chapters on India and Nepal. Comparing the trends in Asian youth cultures with those in the United States, Slater comments, "Teens in Asia and teens in the United States tend to have similar desires and needs, to like similar foods and to enjoy similar types of recreation, while the similarities noted above provide a surface impression that teens in Asia are just like those in America, this is only partly true" (3). Slater sums up, "What remains to be seen is what teens do with their unique heritage and how they, tomorrow's adults, propel their countries ahead" (3). The best thing about the articles in the book is that they provide details of what happens in a typical day of a youth in each country. 
Growing up South Asian: A Brief Trajectory 46

Likewise, Sunaina Marr Maira's milestone work on diaspora youth culture entitled Desi in the House: Indian American Youth Culture in New York City uses "aneclectic theoretical approach, integrating models and concepts from anthropology, sociology, cultural studies, psychology and literary criticism" to analyze "the subjectivity of individual experiences and the implications of collective response to social and material contexts focused on second generation Indian youths [which also implies the youths of the whole Indian sub-continent] in New York” (24). Borrowing the term coined by Appadurai in 1996, Maira's anthropological study of the SA American "youthscape" in New York brings to light the "often hidden contradictions of citizenship and belonging, work and leisure, multiculturalism and education, that second-generation youth manage daily" (17). In spite of its narrow focus on second generation SA youths, it raises a number of pertinent issues relevant to cross-cultural study such as nostalgia, negotiation, ideologies, resistance and ethnic authenticity.

Relating the notion of childhood with the Empire, in Colonial Childhoods: The Juvenile Periphery of India 1850-1945, Sen stresses the need to politicize the nature of childhood and adolescence in order to get a better picture of Indian history under colonial rule. Primarily focused on the study of how the condition of childhood in India was identified and imagined by adults, Sen demonstrates the ways in which the children themselves influenced the processes of identification and imagination (8). According to Sen, "the elite Indians who were deeply ambivalent about the institutionalization of their 'own' children frequently assisted in the colonialization of other inferior natives” (5). Thus, childhood became a window through which "the native elite imagined the impact of colonialism upon the Indian self, derived their reformulations of the self and engaged in the variations of the "passive revolution'” (7). Hence, SA youths have long been drawing the attention of the scholars from diverse disciplines like history, anthropology and social sciences.

Critical analysis of Western youth literature representing South Asia has so far been almost neglected. I do not mean to say that there is no literature depicting SA youths. Meena Khorana's The Indian Subcontinent in Literature for Children and Young Adults, published over two decades ago, lists over nine hundred books produced indigenously from the five major countries in the region, Bangladesh, India, Nepal, Pakistan and Sri Lanka. Although these books (on SA children and youths) were either originally written in English or translated into English by local authors, they demonstrate a significant impact of and on Western tradition of children's literature during and after the British Colonial rule in the region. "Western books on the subcontinent," Khorana argues, "although they are better written, illustrated and produced, nevertheless follow a similar trend in subject matter as the ones published indigenously" (xxiv). Besides Khorana's work and a limited number of journal articles, little critical work has been 
Growing up South Asian: A Brief Trajectory 47

done on the identities of SA youths in Western youth literature. Thus, my scholarship is heavily invested in exploring this relatively neglected territory in the discourses of youth literature originally written in English.

In Western literary imagination, SA youths have occupied a significant space as discussed before ever since the colonial period. A cursory look at the body of youth literature, popular in the West, also reveals the questionable representation of SA characters and settings in the books of writers like Rudyard Kipling (Kim and The Jungle Book) and Herman Hesse (Siddhartha) to the most recent works of Western writers like Suzanne F. Staples (Shabanu trilogy), Patricia McCormick (Sold), Deborah Ellis (The Breadwinner trilogy) and Roland Smith (Peak), to name a few. Likewise, SA diaspora writers have expended considerable amount of ink in representing SA youths in their novels set either in South Asia or in Europe and America. Rushdie's Haroun and the Sea of Stories and Luka and the Fire of Life, Hidier's Born Confused, Desai's The Inheritance of Loss, Mitali Perkins' Secret Keeper and Monsoon Summer, Marina Budhos's Ask Me No Questions, Samrat Upadhyay's The Guru of Love, Selvadurai's Funny Boy and Monica Ali's Brick Lane primarily contain SA characters and settings. Ruskin Bond's contribution to literature for young readers, however, stands out particularly because of his unique subject position as a Western diaspora author based in South Asia (India).

In addition to novels, Western young readers encounter alluring and often disturbing images of SA history, myths, cultures, religions and landscapes that leave them with a craving for the "exotic" land, people and cultures, in the movies like Slumdog Millionaire and Bend it Like Beckham, which portray the lives of SA youths at home or abroad. The other category of texts that present the experiences, problems and potentials of SA youths to the Western young audiences are the novels written in English by home authors (SA) but published both locally in SA countries as well as internationally by multinational companies whether they are targeted for younger audiences or not. Arundhati Roy's God of Small Things is one of this kind which has become popular in both South Asia and the West. Great SA authors like R. K. Narayan, Dhan Gopal Mukerji, Rabindranath Tagore and Laxmi Prasad Devkota are other major writers who have also written in English and published locally by targeting young readers.

Considering the vastness of the area, this paper focused on the encounters of SA youths with their Western counterparts as represented in the novels originally written in English and published and marketed primarily for Western audiences. Although references will be made to many of the texts mentioned above, the analysis primarily relies on Staples' Shabanuand Haveli, Smith's Peak and McCormick's Sold as examples of Western texts. 
Growing up South Asian: A Brief Trajectory 48

Among these authors, Staples's novels Shabanu and Haveli present exemplary accounts preferred byneo-colonialist Western authors who write about SA youths based on the putatively "exotic" and "almost unlivable" world in one or more of the countries in South Asia. Smith's youth hero in Peak encounters the native in their (the native's) homelands, whereas McCormick presents a complex trajectory of a young "brown" female protagonist from Nepal who gets rescued from the abusive "brown men and women" by an unidentified "white man.” Elsewhere, I analyze the novels of each of the categories by problematizing the subject positions of the authors in relation to their oeuvre and the ways in which they handle the forces that disOrient, infantilize, criminalize, exoticize and parentify the youths in and from this region.

\section{Conclusion}

Since the portrayal of encounters between the West and non-West has been my primary criteria for selection of texts for this brief paper, each of the novels from which the insights have been drawn presents one or more critical moments in which the characters representing SA values and worldviews find themselves face to face with those who represent or advocate for Western values. The significance of these moments lies in how they reveal the authors' explicit and implicit ideologies regarding South Asian identity. In spite of the fact that numerous other factors influence what narrative choices are made and how the authors position themselves in the narratives provide effective clues to why they do or do not ascribe agency to specific characters. In other words, the narratives often differ in their treatments of "the other" in accordance with the authors' subject positions (including their race, gender, class and sexuality). In the discursivity of these narratives, the authors appear to be clearly upholding the values of one race, class, gender, or nationality and exoticize, or even demonize those of the other. Others have mixed approaches to cultural differences, ranging from an attitude of ambivalence to a search for abalance between the Western and non-Western cultures. No matter what, growing up South Asian is represented as a complex process due to the tendency of upholding the Western values, despite the problematic relationship of the region with the West.

\section{Works Cited}

Appadurai, Arjun. "Disjuncture and Difference in the Global Cultural Economy." Colonial Discourse and Post-Colonial Theory: A Reader. Edited by P. Williams and L. Chrisman. Harvester Wheatsheaf, 1993, pp, 305-323.

Bend It Like Beckham. Directed by Gurinder Chadha, performances by Parminder Nagra, Keira knightley and Jonathan Rhys Meyers, 2002. https://www.imdb.com/title/tt0286499/ 
Growing up South Asian: A Brief Trajectory 49

Bhabha, Homi K. The Location of Culture. Routledge, 1994.

Budhos, Marina. Ask Me No Questions. Atheneum Books, 2006.

Desai, Kiran. The Inheritance of Loss. Atlantic Monthly, 2006.

Desai Hedier, Tanuja. Born Confused. Scholastic, 2002.

Dirks, Nicholas B. Castes of Mind: Colonialism and the Making of Modern India.

Princeton UP, 2001.

Ellis, Deborah. Parvana's Journey. Groundwood Books, 2002.

- - -. The Bread Winner. Groundwood Books, 2000.

Grace, Daphne. The Woman in the Muslin Mask: Veiling and Identity in Postcolonial

Literature. Pluto Press, 2004.

Guha, Ranajit and Gayatri Spivak, editors. Selected Subaltern Studies. Oxford UP, 1988.

Khorana, Meena, editor. The Indian Subcontinent in Literature for Children and Young

Adults: An Annotated Bibliography of English-Language Books. Greenwood, 1991.

Kipling, Rudyard. Kim. McMillan, 1919.

- - -. The Jungle Book. McMillan, 1894.

Kristeva, Julia. Powers of Horror: An Essay on Abjection. New York. Columbia UP, 1982.

McCormick, Patricia. Sold. Hyperion, 2006.

Maria, Sunaina Marr. Desis in the House: Indian American Youth Culture in New York

City. Temple UP, 2002.

Perkins, Mitali. Secret Keeper. Delacorte Books, 2009.

- - -. Monsoon Summer. Delacorte Books, 2004.

Roy, Arundhati. The God of Small Things. Random House, 1997.

Rushdie, Salman. Haroun and Sea of Stories. Routledge, 1990.

- - -. Luka and the Fire of Life. Random House, 2010.

Sen, Satadru. Colonial Childhoods: The Juvenile Periphery of India 1850-1945.

Anthem, 2005.

Slater, Judith J., editor. Teen Life in Asia. Greenwood Press, 2004.

Upadhyay, Samrat. The Guru of Love. Houghton Mifflin, 2003. 